\title{
Idiopathic REM sleep behavior disorder as a long-term predictor of neurodegenerative disorders
}

\author{
Stephany Fulda
}

Received: 8 May 2011 / Accepted: 14 June 2011 /Published online: 29 June 2011

(C) European Association for Predictive, Preventive and Personalised Medicine 2011

\begin{abstract}
REM sleep behavior disorder (RBD) is a parasomnia characterized by dream-enacting behavior and loss of muscle atonia during REM sleep. Idiopathic RBD occurs in the absence of any neurological disease or other possible cause, is male-predominant and its clinical course is generally chronic progressive. Secondary RBD may be related to neurodegenerative disorders such as multiple system atrophy, Parkinson's disease and Lewy body dementia. Recent long-term prospective studies have shown that $30 \%$ to $65 \%$ of patients with idiopathic RBD will eventually develop a neurodegenerative disorder with the rate of emergence depending on the length of the follow-up period. RBD may therefore be one of the earliest signs of and/or a long-term predictor for neurodegenerative disorders. Because RBD antecedes the development of these disorders by several years or decades, its recognition may enable the delay or prevention of neurodegenerative disorders through the early application of neuroprotective or disease-modifying therapies in the future.
\end{abstract}

Keywords REM sleep behavior disorder P Parkinson's disease $\cdot$ Multiple system atrophy $\cdot$ Dementia with Lewy bodies $\cdot$ Long-term prediction $\cdot$ Prevention

$\begin{array}{ll}\text { Abbrevations } & \\ \text { AD } & \text { Alzheimer's disease } \\ \text { DLB } & \text { Dementia with Lewy bodies } \\ \text { EEG } & \text { Electroencephalography } \\ \text { EMG } & \text { Electromyography }\end{array}$

S. Fulda $(\triangle)$

Max Planck Institute of Psychiatry,

Kraepelinstraße 2-10,

80804 Munich, Germany

e-mail: fulda@mpipsykl.mpg.de

$\begin{array}{ll}\text { iRBD } & \text { Idiopathic REM sleep behavior disorder } \\ \text { MCI } & \text { Minimal cognitive impairment } \\ \text { MSA } & \text { Multiple system atrophy } \\ \text { NDD } & \text { Neurodegenerative disorders } \\ \text { NREM sleep } & \text { non REM sleep } \\ \text { REM sleep } & \text { Rapid eye movement sleep } \\ \text { RBD } & \text { REM sleep behavior disorder } \\ \text { RSWA } & \text { REM sleep without atonia } \\ \text { PD } & \text { Parkinson's disease } \\ \text { PDD } & \text { Parkinson's disease with dementia }\end{array}$

\section{Introduction}

Human sleep is divided into rapid eye movement (REM) sleep and non REM (NREM) sleep. REM sleep is characterized by the prominent rapid eye movements and active paralysis of all the somatic musculature except the diaphragm to permit breathing. REM sleep behavior disorder (RBD) is a parasomnia where the physiological atonia during REM sleep is absent or greatly diminished and is characterized by dream-enacting behavior associated with nightmares. Motor behavior ranges from vocalizations during REM sleep or simple movements to violent complex and lasting enactment of dream content with significant injury to the patient or a bed partner. The diagnostic criteria for RBD according to the international classification of sleep disorders [1] are given in Table 1 and require a nocturnal polysomnography to document REM sleep without atonia in the presence of dream-enacting behavior.

RBD was first described in 1987 by Schenck, Mahowald and co-workers [2]. It is a male-predominant disorder and usually emerges after the age of 50 years but has also been observed in younger patients [1]. At present, its prevalence 
Table 1 Diagnostic criteria of REM sleep behavior disorder (RBD) (taken from [1])

A

REM sleep without atonia:

EMG finding of excessive amounts of sustained or intermittent elevation of submental EMG tone or excessive phasic submental or limb EMG twitching.

B At least one of the following:

(1) History of sleep related injurious, potentially injurious, or disruptive behaviors

(2) Abnormal REM sleep behaviors documented during polysomnographic monitoring

$\mathrm{C}$

Absence of EEG epileptiform activity during REM sleep unless RBD can be clearly distinguished from any concurrent REM sleep related seizure disorder.

D

The sleep disorder is not better explained by another sleep disorder, medical or neurological disorder, mental disorder, medication use, or substance use disorder.

is unknown but estimates range from 0.3 and $0.8 \%$ [1]. The onset of RBD can be gradual or rapid but the course is generally chronic and progressive [2]. Complications can include injuries to the patient or a bed partner, which can be life-threatening [3]. Clonazepam, usually in doses of 0.25 to $0.5 \mathrm{mg} / \mathrm{night}$, is efficacious in the majority of patients and is considered first-line treatment but should be used with cautions in patients with dementia, gait disorders or concomitant obstructive sleep apnea [4-6]. Melatonin has also been effective in some patients with RBD [7-9]. Modifying and maintaining a safe sleeping environment should accompany any therapeutic intervention [5].

In the idiopathic form (iRBD), RBD occurs in the absence of any other associated neurological disorder or possible cause. In contrast, RBD may be secondary to neurological diseases particularly multiple system atrophy (MSA), Parkinson's disease (PD) and dementia with Lewy bodies (DLB) (see below). In addition, medication use has been recognized as a precipitating factor, specifically antidepressants and beta-blockers [10-13].

In iRBD no evidence of neurological disease is found, however, in many iRBD patients subclinical abnormalities have been detected such as olfactory deficits [14-19], cognitive dysfunction [20-22], impaired color vision [19], and subtle cortical EEG slowing [21, 23, 24]. Other findings include dysautonomic abnormalities [25-27], reduced cardiac ${ }^{123}$ I-Metaiodobenzylguanidine scintigraphy [28-31], decreased dopamine transporter imaging [32], and increased substantia nigra echogenicity [33-35]. Follow-up of patients with iRBD shows an increased risk for developing neurodegenerative diseases that strongly depends on the length of the follow-up period. Recent evidence suggests that iRBD is an early sign of a slowly evolving neurodegenerative disorder or a long-term predictor of it. In the following this evidence will be summarized and presented focusing on the prevalence and features of $\mathrm{RBD}$ in neurodegenerative disorders, the emergence of neurodegenerative disorders in long-term follow-up studies of patients with iRBD and baseline differences between iRBD patients who developed a neurodegenerative disease and those who remained disease free.

\section{REM sleep behavior disorder in neurodegenerative diseases}

RBD is frequently encountered in neurodegenerative disorders, particularly in MSA, PD and DLB (Table 2). The majority of patients with MSA will also have RBD with reported prevalences of $80 \%$ to $100 \%$ [10,36-38]. Indeed, RBD is currently considered a red flag for the diagnosis of MSA [39]. Interestingly, the strong male predominance encountered in the idiopathic form and in RBD associated with PD and DLB is less evident in MSA where only $33 \%$ to $61 \%$ of the patients are male $[36,38$, 40]. Concerning the onset of RBD in relation to the occurrence of MSA, studies with retrospective estimates have shown that in $16 \%$ to $54 \%$ of MSA patients RBD preceded the onset of MSA [10, 36, 38, 40, 41]. In one of the studies RBD preceded MSA by a mean of 7 years ( 1 to 38 years) in $52 \%$ of the patients [10], in another [41], RBD occurred 4 years ( 1 to 11 years) earlier in $36 \%$ of MSA patients and in a third [36], RBD preceded MSA by 1 to 19 years in $44 \%$ of the patients.

The prevalence of RBD in PD lies between 30\% and 41\% [42-45]. Between $65 \%$ to $75 \%$ of PD patients with RBD are male $[38,44]$. RBD occurs both in idiopathic PD and PD secondary to genetic mutations [46] and in PD patients that are untreated or treated with dopaminergic substances [10]. RBD is more common in the rigid-akinetic subtype of PD than in the tremoric subtype [47, 48]. Nondemented patients with PD and RBD are more likely to show EEG slowing during wakefulness [49] and poorer cognitive function [50] but RBD in PD patients has also been linked to longer duration of PD [41, 44]. RBD in PD is not associated with age, disease severity, depression, or sleep architecture [10]. RBD preceded PD in $18 \%$ to $25 \%$ of patients [38, 41, 48], on average between 3 ( 1 to 30 years) [41] and 4 years [48]. However, in patients with Parkin mutations, RBD develops after PD onset [46] and RBD rarely precedes PD onset in patients with early onset $\mathrm{PD}(<50$ years) [48]. Interestingly, it seems that in patients with iRBD who subsequently developed PD, the onset of PD is later ( 72 years) than reported for PD patients ( $\sim 62$ years) [51].

The prevalence of RBD in DLB is not as well established and available studies showed prevalences between $40 \%$ [52] and $72 \%$ [53] again with a male predominance [10]. RBD preceded the onset of cognitive complaints and dementia in 
Table 2 REM sleep behavior disorder (RBD) in neurodegenerative disorders

\begin{tabular}{|c|c|c|c|c|}
\hline & \multirow[t]{2}{*}{ Prevalence of RBD } & \multicolumn{2}{|c|}{$\begin{array}{l}\text { RBD preceded onset of } \\
\text { neurodegenerative disorder }\end{array}$} & \multirow[t]{2}{*}{ References } \\
\hline & & in $\%$ of patients & time interval & \\
\hline Multiple system atrophy & $80-100 \%$ & $16-54 \%$ & 4-7 years & {$[10,36-38,40,41]$} \\
\hline Parkinson's disease & $30-41 \%$ & $18-25 \%$ & $3-4$ years & {$[38,41-45,48]$} \\
\hline $\begin{array}{l}\text { Dementia with } \\
\text { Lewy bodies }\end{array}$ & $40-72 \%$ & $71-100 \%$ & $6-10$ years & {$[10,41,52-56]$} \\
\hline
\end{tabular}

the vast majority of patients (71 to $100 \%)[10,41,54,55]$ and the onset of cognitive decline followed on average 6 [54], 9 [55] or 10 years [56] later. Current consensus criteria for DLB consider RBD as a suggestive feature of this disease [57] and it is thought that the clinical combination of dementia and RBD very likely indicates underlying Lewy body disease, i.e. DLB and PD with dementia (PDD) [10].

All three disorders - MSA, PD, and DLB - are characterized by intraneural deposition of $\alpha$-synuclein and therefore it has been speculated that the RBD may be linked to synuclein pathology [52]. RBD has also been observed in cases with pure autonomic failure [58, 59]. Until recently, RBD has been considered comparatively rare in tauopathies, however, newer studies have reported a RBD or REM sleep without atonia (RSWA) also in progressive supranuclear palsy (27\%) [60] and Alzheimer's disease (7\% RBD, 29\% RSWA) [61]. However, RBD has not been observed in pallindopontonigral degeneration [62]. Also, so far no case of RBD in a patient with Pick's disease has been reported [63]. RBD has also been associated to autoimmune mechanisms as REM sleep without atonia is frequently found in narco- lepsy [64-67], another rare sleep disorder with a possible autoimmune background. Similarly, RBD has been observed in 5 of 6 patients with nonparaneoplastic limbic encephalitis associated with antibodies to voltage-gated potassium channels [68]. Interestingly, symptoms of RBD coincided with the onset of the disorder and in 3 of the patients immunosuppression resulted in a resolution of RBD in parallel with the remission of the limbic syndrome [68].

In summary, at present the available evidence shows that RBD is a common feature of synucleinopathies, especially MSA, DLB, and PD. Nevertheless, among these disorders RBD is distinctly more prevalent in MSA, maybe because brainstem cell loss is widespread and severe in this disorder. Retrospective assessment indicates that RBD frequently precedes the onset of these disorders but this seems to be most pronounced in DLB probably reflecting the differences in clinical course and progression in these disorders. RBD has also been observed in tauopathies and disorders with a neuroimmunological background, however, at the moment the association with synucleinopathies outweighs that with any other.
Table 3 New onset of neurodegenerative disorders in prospective follow-up studies of patients with idiopathic REM sleep behavior disorder
$A D$ Alzheimer's disease; $D L B$ dementia with Lewy bodies; $i R B D$ idiopathic REM sleep behavior disorder; $M C I$ minimal cognitive impairment; $M S A$ multiple system atrophy; $P D$ Parkinson's disease; $P D D$ Parkinson's disease dementia; $y$ years

\begin{tabular}{|c|c|c|c|c|c|}
\hline \multirow[t]{2}{*}{ Study } & \multirow[t]{2}{*}{ Subjects } & \multirow{2}{*}{$\begin{array}{l}\text { Follow-up } \\
\text { time }\end{array}$} & \multirow[t]{2}{*}{ Prevalence } & \multicolumn{2}{|l|}{ Time since } \\
\hline & & & & RBD onset & $\begin{array}{l}\text { RBD } \\
\text { diagnosis }\end{array}$ \\
\hline $\begin{array}{l}\text { Schenck et al. } \\
1996[77]\end{array}$ & $\begin{array}{l}29 \text { patients } \geq 50 \text { y } \\
\text { with iRBD }\end{array}$ & $\sim 13 \mathrm{y}$ & $\begin{array}{l}38 \%(n=11) \mathrm{PD} \\
{[8 \text { definite } \mathrm{PD}, 2 \text { probable }} \\
\mathrm{PD}, 1 \text { possible } \mathrm{PD}]\end{array}$ & $\sim 13 \mathrm{y}$ & $\sim 4 \mathrm{y}$ \\
\hline $\begin{array}{l}\text { Schenck et al. } \\
2003[78]\end{array}$ & & $\sim 20 \mathrm{y}$ & $\begin{array}{l}65 \%(n=17 \text { of } 26) \\
{[13 \mathrm{PD}, 1 \mathrm{PDD}, 2 \mathrm{DLB}, 1 \mathrm{AD}]}\end{array}$ & $\sim 13$ y (3-29) & \\
\hline $\begin{array}{l}\text { Iranzo et al. } \\
2006[51]\end{array}$ & $\begin{array}{l}44 \text { patients } \\
\text { with iRBD }\end{array}$ & $\sim 5 \mathrm{y}(2-15 \mathrm{y})$ & $\begin{array}{l}45 \%(n=20) \\
{[7 \mathrm{PD}, 2 \mathrm{PDD}, 6 \mathrm{DLB}} \\
1 \mathrm{MSA}, 4 \mathrm{MCI}]\end{array}$ & $\sim 12 \mathrm{y}$ & $\sim 4 \mathrm{y}$ \\
\hline $\begin{array}{l}\text { Iranzo et al. } \\
2008[80]\end{array}$ & & $\sim 7 \mathrm{y}$ & $\begin{array}{l}64 \%(n=28) \\
{[6 \mathrm{PD}, 4 \mathrm{PDD}, 8 \mathrm{DLB}} \\
1 \mathrm{MSA}, 9 \mathrm{MCI}]\end{array}$ & & \\
\hline $\begin{array}{l}\text { Postuma et al. } \\
2009 \text { [81] }\end{array}$ & $\begin{array}{l}93 \text { patients } \\
\text { with iRBD }\end{array}$ & $\sim 5 \mathrm{y}$ & $\begin{array}{l}30 \%(n=26) \\
{[14 \mathrm{PD}, 7 \mathrm{DLB}, 4 \mathrm{AD}} \\
1 \mathrm{MSA}]\end{array}$ & $\sim 12 \mathrm{y}$ & \\
\hline $\begin{array}{l}\text { Tippman-Peikert et al. } \\
2006 \text { [79] }\end{array}$ & $\begin{array}{l}23 \text { patients } \\
\text { with iRBD }\end{array}$ & $\sim 11 \mathrm{y}$ & $\begin{array}{l}65 \%(n=15) \\
{[1 \text { PD, } 3 \text { DLB, } 1 \text { dementia, }} \\
10 \text { reported symptoms highly } \\
\text { suggestive of a parkinsonian } \\
\text { or dementing disorder }]\end{array}$ & & \\
\hline
\end{tabular}




\section{RBD as a long-term predictor for neurodegenerative disorders}

There are several case studies reporting the new onset of neurodegenerative disorders years to decades after the onset of RBD. This has been documented for Parkinson's disease [69], Lewy body disorder [70-73], multiple system atrophy [72], and shy drager syndrome [74] and periods of 2 to 50 years [75]. Interestingly, in two of these cases Lewy body disease was only discovered at autopsy $[70,76]$.

In systematic long-term prospective studies the percentage of patients with iRBD who will eventually develop a neurodegenerative disorder ranges from $30 \%$ to $65 \%$ strongly depending on the length of the follow-up period (Table 3). Schenck and co-workers were the first to report that during a follow-up time of 13 years $38 \%$ of a group of 29 male iRBD patients above 50 years of age developed PD [77]. In a subsequent follow-up 7 years later, 65\% had developed a neurodegenerative disorder [78]. Similar results were reported for 23 patients with iRBD of which $65 \%$ developed a neurodegenerative disorder during an average follow-up time of 11 years [79]. In an even larger case series of 44 consecutive iRBD patients, $45 \%$ developed PD, DLB, MSA or minimal cognitive impairment (MCI) after an average follow-up time of 5 years [51] and $64 \%$ after 7 years [80]. In the largest case series to date, 26 of 93 patients $(30 \%)$ with iRBD developed neurodegenerative disorders after an average follow-up time of 5 years [81]. In the same study [81], the authors conducted a formal survival analysis and estimated the risk for the development of neurodegenerative disorders as $18 \%$ for a 5 year period, $41 \%$ for a 10 -year period, and $52 \%$ for a 12 -year period. Summarizing these four case series, across average follow-up periods of 5 to 20 years 86 of 189 patients (46\%) with iRBD developed a neurodegenerative disorder. The average time between the onset of RBD and the onset of the neurodegenerative disorder was 12 years and for the 76 patients with a

Table 4 Possible predictors for the development of neurodegenerative disorders in RBD: Baseline differences between iRBD patients who developed neurodegenerative disorders and $\mathrm{iRBD}$ patients who remained disease free

\begin{tabular}{|c|c|c|c|}
\hline Study & Subjects & Follow-up time & Measured function/Main findings \\
\hline $\begin{array}{l}\text { Schenck et al. } \\
1996[77]\end{array}$ & $\begin{array}{l}29 \text { male patients } \geq 50 \text { y with iRBD } \\
\text { of which } 11 \text { developed PD }\end{array}$ & $\sim 13 \mathrm{y}$ & $\begin{array}{l}\text { Sleep, tonic and phasic chin EMG during REM sleep: } \\
\text { Patients with PD had increased REM sleep and periodic } \\
\text { leg movements at baseline. } \\
\text { No difference in tonic or phasic EMG during REM, other } \\
\text { sleep parameters. }\end{array}$ \\
\hline $\begin{array}{l}\text { Iranzo et al. } \\
2011[24]\end{array}$ & $\begin{array}{l}23 \text { iRBD of which } 10 \text { developed } \\
\text { MCI } 10 \text { healthy controls }\end{array}$ & $2.4 \pm 1.6 \mathrm{y}$ & $\begin{array}{l}\text { Quantitative EEG (wake, REM sleep): } \\
\text { Compared to healthy controls both RBD groups showed } \\
\text { slowing of EEG during wakefulness and REM sleep. } \\
\text { No significant difference between RBD with and without } \\
\text { MCI but trend towards greater EEG slowing during wakefulness. }\end{array}$ \\
\hline $\begin{array}{l}\text { Iranzo et al. } \\
2010[86]\end{array}$ & $\begin{array}{l}43 \text { iRBD of which } 8 \text { developed } \\
\text { NDD }^{\text {a }} 18 \text { and } 143 \text { healthy controls }\end{array}$ & $\sim 2.5 \mathrm{y}$ & $\begin{array}{l}{ }^{123} \text { I-FP-CIT striatal binding, substantia nigra hyperechogenicity: } \\
27(63 \%) \text { had reduced }{ }^{123} \text { I-FP-CIT striatal binding }(40 \%) \\
\text { and/or substantia nigra hyperechogeneicity }(36 \%) \text {. } \\
\text { All } 8 \text { with MCI had reduced }{ }^{123} \text { I-FP-CIT uptake or substantia } \\
\text { nigra hyperechogenicity at baseline; } 30 \%(8-27) \text { of those } \\
\text { with abnormal imaging at baseline developed NDD). } \\
\text { None of the } 15 \text { iRBD patients with normal neuroimaging } \\
\text { developed NDD. }\end{array}$ \\
\hline Postuma et al. 2010 [85] & $\begin{array}{l}26 \text { iRBD with development of } \\
\text { NDD } 26 \text { matched iRBDD } \\
\text { without } \text { NDD }^{\mathrm{b}}\end{array}$ & $\sim 7 \mathrm{y}$ & $\begin{array}{l}\text { Sleep, tonic and phasic chin EMG during REM sleep: } \\
\text { Patients with NDD had increased percentage of tonic } \\
\text { submental EMG activity at baseline (more severe loss } \\
\text { of REM atonia) and increased stage } 1 \text { sleep. } \\
\text { No difference for phasic submental EMG or other sleep } \\
\text { parameters. }\end{array}$ \\
\hline $\begin{array}{l}\text { Postuma et al. } \\
2011 \text { [87] }\end{array}$ & $\begin{array}{l}62 \text { iRBD of which } 21 \\
\text { developed NDD }\end{array}$ & $\sim 5 \mathrm{y}$ & $\begin{array}{l}\text { Olfaction, color vision testing: } \\
\text { Patients who developed NDD had more severe abnormalities } \\
\text { of olfaction and color vision at baseline }\end{array}$ \\
\hline $\begin{array}{l}\text { Postuma et al. } \\
2010 \text { [27] }\end{array}$ & $\begin{array}{l}42 \text { iRBD of which } 21 \\
\text { developed NDD }\end{array}$ & $\sim 7 \mathrm{y}$ & $\begin{array}{l}\text { Cardiac autonomic function: } \\
\text { No difference between patient groups for any } \\
\text { measure of cardiac autonomic function }\end{array}$ \\
\hline
\end{tabular}

$A D$ Alzheimer's disease; $D L B$ dementia with Lewy bodies; $i R B D$ idiopathic REM sleep behavior disorder; $M C I$ minimal cognitive impairment; $M S A$ multiple system atrophy; $N D D$ neurodegenerative disorder; $P D$ Parkinson's disease; $P D D$ Parkinson's disease dementia; $y$ years

${ }^{\mathrm{a}} 5 \mathrm{PD}, 2 \mathrm{DLB}, 1 \mathrm{MSA}^{\mathrm{b}}{ }^{12} \mathrm{PD}, 1 \mathrm{MSA}, 7 \mathrm{DLB}, 6$ dementia; ${ }^{\mathrm{c}} 16 \mathrm{PDD}, 4 \mathrm{PD}, 1$ dementia; ${ }^{\mathrm{d}} 11 \mathrm{PD}, 1 \mathrm{MSA}, 5 \mathrm{DLB}, 4 \mathrm{AD}$ 
definite diagnosis the new onset disorder was Parkinson's disease in $39(51 \%)$, Lewy body disease in $20(26 \%)$, minimal cognitive impairment in $9(12 \%)$, Alzheimer's disease in $5(7 \%)$, MSA in $2(3 \%)$ and dementia in 1 patient (Table 2).

Long-term studies in iRBD patients have shown that over time excessive phasic and tonic muscle activity during REM sleep increases [82], cognitive functioning declines [83], and nigrostriatal presynaptic dopaminergic function possible decreases [84] compatible with a general neurodegenerative process.

Possible predictors for the future development of neurodegenerative disorders in patients with $\mathrm{R} B \mathrm{BD}$ have emerged from studies that compared baseline measurement of iRBD patients with subsequent neurodegenerative disorders to disease-free iRBD patients (Table 4). Distinguishing characteristics in these studies were an increase in REM sleep [77] or stage 1 sleep [85], increased tonic submental EMG activity [85], increased striatal dopamine dysfunction or substantia nigra hyperechogenicity [86], more severe abnormalities of olfaction and color vision [87] and a tendency towards more pronounced EEG slowing during wakefulness [24] (Table 3). Interestingly, cardiac autonomic function which differs between RBD and healthy controls [25, 26], did not distinguish between RBD patients with subsequent neurodegenerative disorders and disease free patients, suggesting that autonomic dysfunction in RBD may be independent from associated PD or LBD [27]. Currently, these promising studies await independent replication. For the future it is hoped that the timely identification of iRBD patients who will develop a neurodegenerative disorder provides a window of opportunity for prevention or early treatment of these disorders.

\section{Summary and outlook}

$\mathrm{RBD}$ is relatively rare sleep disorder with a male predominance that is characterized by dream-enactment and loss of REM sleep atonia. Secondary RBD is frequently encountered in neurodegenerative disorders and in particular in synucleinopathies such as MSA, DLB, and PD. Retrospective assessment of the onset of RBD in these disorders suggests that RBD precedes the onset of these synucleinopathies in a significant proportion by several years to decades. This is confirmed by prospective long-term studies of patients with iRBD, free of neurological disorders at the time of the diagnosis or RBD. These studies showed that up to $60 \%$ of patients with iRBD will subsequently develop a neurodegenerative disorder, most frequently PD and DLB. Again, the time span between the onset of RBD and the onset of the subsequent neurodegenerative disorder was around a decade with increasing conversion rates across longer the follow-up periods. First studies have also explored possible predictors for the development of subsequent neurodegenerative diseases in iRBD patients, but more research is needed in this area.

RBD can be seen as a long-term predictor for the development of neurodegenerative disorders. Most likely it is one of the earliest signs of these disorders. Indeed, for some of these disorders such as PD, it is now apparent that the preclinical phase can extent to 20 years or longer before the motor manifestations [88, 89] and among the symptoms that precede PD by 10 to 20 years are constipation, anemia, and anxiety disorders [89]. Possible predictors for the development of neurodegenerative disorders in patients with iRBD include increased REM or stage 1 sleep, increased submental EMG activity during REM sleep, striatal dopamine dysfunction and substantia nigra hyperechogenicity, more severe abnormalities of olfaction and color vision and EEG slowing during wakefulness. Nocturnal polysomnograpy, imaging of dopamine metabolism, transcranial sonography, olfactory and color testing and daytime EEG may therefore by clinical tools to identify RBD patients at an increased risk for future neurodegenerative disorders. Because RBD precedes the development of neurodegenerative disorders by years to decades, its timely recognition in patients may offer a window of opportunity where the early application of neuroprotective or disease modifying therapies is hoped to delay or prevent the onset of neurodegenerative disorders.

Conflict of interest statement There is no conflict of interest

\section{References}

1. American Academy of Sleep Medicine. The international classification of sleep disorders: diagnostic and coding manual. 2nd ed. Westchester: American Academy of Sleep Medicine; 2005.

2. Schenck CH, Bundlie SR, Ettinger MG, Mahowald MW. Chronic behavioral disorders of human REM sleep: a new category of parasomnia. Sleep. 1986;9:293-308.

3. Schenck CH, Lee SA, Bornemann MAC, Mahowald MW. Potentially lethal behaviors associated with rapid eye movement sleep behavior disorder: review of the literature and forensic implications. J Forensic Sci. 2009;54:1475-84.

4. Gagnon J-F, Postuma RB, Montplaisir J. Update on the pharmacology of REM sleep behavior disorder. Neurology. 2006;67:742-7.

5. Aurora RN, Zak RS, Maganti RK, Auerbach SH, Casey KR, Chowdhuri $\mathrm{S}$, et al. Best practice guide for the treatment of REM sleep behavior disorder (RBD). J Clin Sleep Med. 2010;6:85-95.

6. Schuld A, Kraus T, Haack M, Hinze-Selch D, Pollmächer T. Obstructive sleep apnea syndrome induced by clonazepam in a narcoleptic patient with REM-sleep-behavior disorder. J Sleep Res. 1999;8:321-2.

7. Boeve BF, Silber MH, Ferman TJ. Melatonin for treatment of REM sleep behavior disorder in neurologic disorders: results in 14 patients. Sleep Med. 2003;4:281-4. 
8. Kunz D, Bes F. Melatonin as a therapy in REM sleep behavior disorder patients: an open-labeled pilot study on the possible influence of melatonin on REM-sleep regulation. Mov Disord. 1999;14:507-11.

9. Kunz D, Mahlberg R. A two-part, double-blind, placebo-controlled trial of exogenous melatonin in REM sleep behaviour disorder. J Sleep Res. 2010;19:591-6.

10. Iranzo A, Santamaria J, Tolosa E. The clinical and pathophysiological relevance of REM sleep behavior disorder in neurodegenerative diseases. Sleep Med Rev. 2009;13:385-401.

11. Hoque R, Chesson AL. Pharmacologically induced/exacerbated restless legs syndrome, periodic limb movements of sleep, and REM behavior disorder/REM sleep without atonia: literature review, qualitative scoring, and comparative analysis. J Clin Sleep Med. 2010;6:79-83.

12. Morrison I, Frangulyan R, Riha RL. Beta-blockers as a cause of violent rapid eye movement sleep behavior disorder: a poorly recognized but common cause of violent parasomnias. Am J Med. 2011;124:e11.

13. Teman PT, Tippmann-Peikert M, Silber MH, Slocumb NL, Auger RR. Idiopathic rapid-eye-movement sleep disorder: associations with antidepressants, psychiatric diagnoses, and other factors, in relation to age of onset. Sleep Med. 2009;10:60-5.

14. Fantini ML, Postuma RB, Montplaisir J, Ferini-Strambi L. Olfactory deficit in idiopathic rapid eye movements sleep behavior disorder. Brain Res Bull. 2006;70:386-90.

15. Miyamoto T, Miyamoto M, Iwanami M, Hirata K. Olfactory dysfunction in Japanese patients with idiopathic REM sleep behavior disorder: comparison of data using the university of Pennsylvania smell identification test and odor stick identification test for Japanese. Mov Disord. 2010;25:1524-6.

16. Miyamoto T, Miyamoto M, Iwanami M, Hirata K, Kobayashi M, Nakamura $M$, et al. Olfactory dysfunction in idiopathic REM sleep behavior disorder. Sleep Med. 2010;11:458-61.

17. Miyamoto T, Miyamoto M, Iwanami M, Suzuki K, Inoue Y, Hirata $\mathrm{K}$. Odor identification test as an indicator of idiopathic REM sleep behavior disorder. Mov Disord. 2009;24:268-73.

18. Stiasny-Kolster K, Clever S-C, Möller JC, Oertel WH, Mayer G. Olfactory dysfunction in patients with narcolepsy with and without REM sleep behaviour disorder. Brain. 2007; 130:442-9.

19. Postuma RB, Lang AE, Massicotte-Marquez J, Montplaisir J. Potential early markers of Parkinson disease in idiopathic REM sleep behavior disorder. Neurology. 2006;66:845-51.

20. Ferini-Strambi L, Di Gioia MR, Castronovo V, Oldani A, Zucconi M, Cappa SF. Neuropsychological assessment in idiopathic REM sleep behavior disorder (RBD): does the idiopathic form of RBD really exist? Neurology. 2004;62:41-5.

21. Massicotte-Marquez J, Décary A, Gagnon J-F, Vendette M, Mathieu A, Postuma RB, et al. Executive dysfunction and memory impairment in idiopathic REM sleep behavior disorder. Neurology. 2008;70:1250-7.

22. Terzaghi M, Sinforiani E, Zucchella C, Zambrelli E, Pasotti C, Rustioni V, et al. Cognitive performance in REM sleep behaviour disorder: a possible early marker of neurodegenerative disease? Sleep Med. 2008;9:343-51.

23. Fantini ML, Gagnon J-F, Petit D, Rompré S, Décary A, Carrier J, et al. Slowing of electroencephalogram in rapid eye movement sleep behavior disorder. Ann Neurol. 2003;53:774-80.

24. Iranzo A, Isetta V, Molinuevo JL, Serradell M, Navajas D, Farre $\mathrm{R}$, et al. Electroencephalographic slowing heralds mild cognitive impairment in idiopathic REM sleep behavior disorder. Sleep Med. 2011;11:534-9.

25. Ferini-Strambi L, Oldani A, Zucconi M, Smirne S. Cardiac autonomic activity during wakefulness and sleep in REM sleep behavior disorder. Sleep. 1996;19:367-9.
26. Lanfranchi PA, Fradette L, Gagnon J-F, Colombo R, Montplaisir J. Cardiac autonomic regulation during sleep in idiopathic REM sleep behavior disorder. Sleep. 2007;30:1019-25.

27. Postuma RB, Lanfranchi PA, Blais H, Gagnon J-F, Montplaisir JY. Cardiac autonomic dysfunction in idiopathic REM sleep behavior disorder. Mov Disord. 2010;25:2304-10.

28. Kashihara K, Imamura T, Shinya T. Cardiac 123I-MIBG uptake is reduced more markedly in patients with REM sleep behavior disorder than in those with early stage Parkinson's disease. Parkinsonism Relat Disord. 2010;16:252-5.

29. Miyamoto T, Miyamoto M, Inoue Y, Usui Y, Suzuki K, Hirata K. Reduced cardiac 123I-MIBG scintigraphy in idiopathic REM sleep behavior disorder. Neurology. 2006;67:2236-8.

30. Miyamoto T, Miyamoto M, Iwanami M, Hirata K. Cardiac (123)IMIBG accumulation in Parkinson's disease differs in association with REM sleep behavior disorder. Parkinsonism Relat Disord. 2011;17:219-20.

31. Miyamoto T, Miyamoto M, Suzuki K, Nishibayashi M, Iwanami M, Hirata K. 123I-MIBG cardiac scintigraphy provides clues to the underlying neurodegenerative disorder in idiopathic REM sleep behavior disorder. Sleep. 2008;31:717-23.

32. Eisensehr I, Linke R, Noachtar S, Schwarz J, Gildehaus FJ, Tatsch $\mathrm{K}$. Reduced striatal dopamine transporters in idiopathic rapid eye movement sleep behaviour disorder. Comparison with Parkinson's disease and controls. Brain. 2000;123:1155-60.

33. Iwanami M, Miyamoto T, Miyamoto M, Hirata K, Takada E. Relevance of substantia nigra hyperechogenicity and reduced odor identification in idiopathic REM sleep behavior disorder. Sleep Med. 2010;11:361-5.

34. Stockner H, Iranzo A, Seppi K, Serradell M, Gschliesser V, Sojer $\mathrm{M}$, et al. Midbrain hyperechogenicity in idiopathic REM sleep behavior disorder. Mov Disord. 2009;24:1906-9.

35. Unger MM, Möller JC, Stiasny-Kolster K, Mankel K, Berg D, Walter $\mathrm{U}$, et al. Assessment of idiopathic rapid-eye-movement sleep behavior disorder by transcranial sonography, olfactory function test, and FP-CIT-SPECT. Mov Disord. 2008;23:596-9.

36. Plazzi G, Corsini R, Provini F, Pierangeli G, Martinelli P, Montagna P, et al. REM sleep behavior disorders in multiple system atrophy. Neurology. 1997;48:1094-7.

37. Tachibana N, Kimura K, Kitajima K, Shinde A, Kimura J, Shibasaki H. REM sleep motor dysfunction in multiple system atrophy: with special emphasis on sleep talk as its early clinical manifestation. J Neurol Neurosurg Psychiatr. 1997;63:678-81.

38. Iranzo A, Santamaría J, Rye DB, Valldeoriola F, Martí MJ, Muñoz E, et al. Characteristics of idiopathic REM sleep behavior disorder and that associated with MSA and PD. Neurology. 2005;65:247-52.

39. Köllensperger M, Geser F, Seppi K, Stampfer-Kountchev M, Sawires M, Scherfler C, et al. Red flags for multiple system atrophy. Mov Disord. 2008;23:1093-9.

40. Vetrugno R, Provini F, Cortelli P, Plazzi G, Lotti EM, Pierangeli G, et al. Sleep disorders in multiple system atrophy: a correlative video-polysomnographic study. Sleep Med. 2004;5:21-30.

41. Olson EJ, Boeve BF, Silber MH. Rapid eye movement sleep behaviour disorder: demographic, clinical and laboratory findings in 93 cases. Brain. 2000;123:331-9.

42. Gagnon JF, Bédard MA, Fantini ML, Petit D, Panisset M, Rompré $\mathrm{S}$, et al. REM sleep behavior disorder and REM sleep without atonia in Parkinson's disease. Neurology. 2002;59:585-9.

43. De Cock VC, Vidailhet M, Leu S, Texeira A, Apartis E, Elbaz A, et al. Restoration of normal motor control in Parkinson's disease during REM sleep. Brain. 2007;130:450-6.

44. Wetter TC, Trenkwalder C, Gershanik O, Högl B. Polysomnographic measures in Parkinson's disease: a comparison between patients with and without REM sleep disturbances. Wien Klin Wochenschr. 2001;113:249-53. 
45. Diederich NJ, Vaillant M, Mancuso G, Lyen P, Tiete J. Progressive sleep "destructuring" in Parkinson's disease. A polysomnographic study in 46 patients. Sleep Med. 2005;6:313-8.

46. Kumru H, Santamaria J, Tolosa E, Valldeoriola F, Muñoz E, Marti MJ, et al. Rapid eye movement sleep behavior disorder in parkinsonism with parkin mutations. Ann Neurol. 2004;56:599603.

47. Postuma RB, Gagnon JF, Vendette M, Charland K, Montplaisir J. REM sleep behaviour disorder in Parkinson's disease is associated with specific motor features. J Neurol Neurosurg Psychiatr. 2008;79:1117-21.

48. Kumru H, Santamaria J, Tolosa E, Iranzo A. Relation between subtype of Parkinson's disease and REM sleep behavior disorder. Sleep Med. 2007;8:779-83.

49. Gagnon J-F, Fantini ML, Bédard M-A, Petit D, Carrier J, Rompré $\mathrm{S}$, et al. Association between waking EEG slowing and REM sleep behavior disorder in PD without dementia. Neurology. 2004;62:401-6.

50. Vendette M, Gagnon J-F, Décary A, Massicotte-Marquez J, Postuma RB, Doyon J, et al. REM sleep behavior disorder predicts cognitive impairment in Parkinson disease without dementia. Neurology. 2007;69:1843-9.

51. Iranzo A, Molinuevo JL, Santamaría J, Serradell M, Martí MJ, Valldeoriola F, et al. Rapid-eye-movement sleep behaviour disorder as an early marker for a neurodegenerative disorder: a descriptive study. Lancet Neurol. 2006;5:572-7.

52. Boeve BF, Silber MH, Ferman TJ, Lucas JA, Parisi JE. Association of REM sleep behavior disorder and neurodegenerative disease may reflect an underlying synucleinopathy. Mov Disord. 2001;16:622-30.

53. Ferman TJ, Smith GE, Boeve BF, Ivnik RJ, Petersen RC, Knopman D, et al. DLB fluctuations: specific features that reliably differentiate DLB from AD and normal aging. Neurology. 2004;62:181-7.

54. Boeve BF, Silber MH, Ferman TJ, Kokmen E, Smith GE, Ivnik $\mathrm{RJ}$, et al. REM sleep behavior disorder and degenerative dementia: an association likely reflecting Lewy body disease. Neurology. 1998;51:363-70.

55. Ferman TJ, Boeve BF, Smith GE, Silber MH, Kokmen E, Petersen $\mathrm{RC}$, et al. REM sleep behavior disorder and dementia: cognitive differences when compared with AD. Neurology. 1999;52:951-7.

56. Boeve BF, Silber MH, Parisi JE, Dickson DW, Ferman TJ, Benarroch EE, et al. Synucleinopathy pathology and REM sleep behavior disorder plus dementia or parkinsonism. Neurology. 2003;61:40-5.

57. McKeith IG, Dickson DW, Lowe J, Emre M, O’Brien JT, Feldman $\mathrm{H}$, et al. Diagnosis and management of dementia with Lewy bodies: third report of the DLB Consortium. Neurology. 2005; 65:1863-72.

58. Sforza E, Krieger J, Petiau C. REM sleep behavior disorder: clinical and physiopathological findings. Sleep Med Rev. 1997;1:57-69.

59. Weyer A, Minnerop M, Abele M, Klockgether T. REM sleep behavioral disorder in pure autonomic failure (PAF). Neurology. 2006;66:608-9.

60. Arnulf I, Merino-Andreu M, Bloch F, Konofal E, Vidailhet M, Cochen V, et al. REM sleep behavior disorder and REM sleep without atonia in patients with progressive supranuclear palsy. Sleep. 2005;28:349-54.

61. Gagnon J-F, Petit D, Fantini ML, Rompré S, Gauthier S, Panisset $\mathrm{M}$, et al. REM sleep behavior disorder and REM sleep without atonia in probable Alzheimer disease. Sleep. 2006;29:1321-5.

62. Boeve BF, Lin S-C, Strongosky A, Dickson DW, Wszolek ZK. Absence of rapid eye movement sleep behavior disorder in 11 members of the pallidopontonigral degeneration kindred. Arch Neurol. 2006;63:268-72.
63. Gagnon J-F, Postuma RB, Mazza S, Doyon J, Montplaisir J. Rapid-eye-movement sleep behaviour disorder and neurodegenerative diseases. Lancet Neurol. 2006;5:424-32.

64. Dauvilliers Y, Rompré S, Gagnon J-F, Vendette M, Petit D, Montplaisir J. REM sleep characteristics in narcolepsy and REM sleep behavior disorder. Sleep. 2007;30:844-9.

65. Mayer M-E. Motor dyscontrol in sleep of narcoleptic patients (a lifelong development?). J Sleep Res. 1993;2:143-8.

66. Nightingale S, Orgill JC, Ebrahim IO, de Lacy SF, Agrawal S, Williams AJ. The association between narcolepsy and REM behavior disorder (RBD). Sleep Med. 2005;6:253-8.

67. Schenck CH, Mahowald MW. Motor dyscontrol in narcolepsy: rapid-eye-movement (REM) sleep without atonia and REM sleep behavior disorder. Ann Neurol. 1992;32:3-10.

68. Iranzo A, Graus F, Clover L, Morera J, Bruna J, Vilar C, et al. Rapid eye movement sleep behavior disorder and potassium channel antibody-associated limbic encephalitis. Ann Neurol. 2006;59:178-81.

69. Tan A, Salgado M, Fahn S. Rapid eye movement sleep behavior disorder preceding Parkinson's disease with therapeutic response to levodopa. Mov Disord. 1996;11:214-6.

70. Uchiyama M, Isse K, Tanaka K, Yokota N, Hamamoto M, Aida S, et al. Incidental Lewy body disease in a patient with REM sleep behavior disorder. Neurology. 1995;45:709-12.

71. Turner RS, D'Amato CJ, Chervin RD, Blaivas M. The pathology of REM sleep behavior disorder with comorbid Lewy body dementia. Neurology. 2000;55:1730-2.

72. Tison F, Wenning GK, Quinn NP, Smith SJ. REM sleep behaviour disorder as the presenting symptom of multiple system atrophy. J Neurol Neurosurg Psychiatr. 1995;58:379-80.

73. Schenck CH, Mahowald MW, Anderson ML, Silber MH, Boeve BF, Parisi JE. Lewy body variant of Alzheimer's disease (AD) identified by postmortem ubiquitin staining in a previously reported case of $\mathrm{AD}$ associated with REM sleep behavior disorder. Biol Psychiatr. 1997;42:527-8.

74. Wright BA, Rosen JR, Buysse DJ, Reynolds CF, Zubenko GS. Shy-Drager syndrome presenting as a REM behavioral disorder. J Geriatr Psychiatry Neurol. 1990;3:110-3.

75. Claassen DO, Josephs KA, Ahlskog JE, Silber MH, TippmannPeikert M, Boeve BF. REM sleep behavior disorder preceding other aspects of synucleinopathies by up to half a century. Neurology. 2010;75:494-9.

76. Boeve BF, Dickson DW, Olson EJ, Shepard JW, Silber MH, Ferman TJ, et al. Insights into REM sleep behavior disorder pathophysiology in brainstem-predominant Lewy body disease. Sleep Med. 2007;8:60-4.

77. Schenck CH, Bundlie SR, Mahowald MW. Delayed emergence of a parkinsonian disorder in $38 \%$ of 29 older men initially diagnosed with idiopathic rapid eye movement sleep behavior disorder. Neurology. 1996;46:388-93.

78. Schenck C, Bundlie S, Mahowald M. REM sleep behaviour disorder (RBD) delayed emergence of parkinsonism and/or dementia in $65 \%$ of older men initially diagnosed with idiopathic $\mathrm{RBD}$, and an analysis of the maximum and minimum tonic and/or phasic electromyographic abnormalities found during REM sleep. Sleep. 2003;26(Abstract Suppl):A316.

79. Tippman-Peikert M, Olson EJ, Boeve B, Silber MH. Idiopathic REM sleep behavior disorder: a follow-up of 39 patients. Sleep. 2006;29(Abstract Suppl):A272.

80. Iranzo A, Molinuevo J, Santamaria J, Serradell M, Marti M, Valledeoriola F, et al. Sixty-four percent of patients with idiopathic REM sleep behavior disorder developed a neurological disorder after a mean clinical follow-up of seven years. Sleep. 2008;31 (Abstract Suppl):A280.

81. Postuma RB, Gagnon JF, Vendette M, Fantini ML, MassicotteMarquez J, Montplaisir J. Quantifying the risk of neurodegenerative 
disease in idiopathic REM sleep behavior disorder. Neurology. 2009;72:1296-300.

82. Iranzo A, Ratti PL, Casanova-Molla J, Serradell M, Vilaseca I, Santamaria J. Excessive muscle activity increases over time in idiopathic REM sleep behavior disorder. Sleep. 2009;32:1149-53.

83. Fantini ML, Farini E, Ortelli P, Zucconi M, Manconi M, Cappa S, et al. Longitudinal study of cognitive function in idiopathic REM sleep behavior disorder. Sleep. 2011;34:619-25.

84. Miyamoto T, Orimo S, Miyamoto M, Hirata K, Adachi T, Hattori $\mathrm{R}$, et al. Follow-up PET studies in case of idiopathic REM sleep behavior disorder. Sleep Med. 2010;11:100-1.

85. Postuma RB, Gagnon JF, Rompré S, Montplaisir JY. Severity of REM atonia loss in idiopathic REM sleep behavior disorder predicts Parkinson disease. Neurology. 2010;74:239-44.
86. Iranzo A, Lomeña F, Stockner H, Valldeoriola F, Vilaseca I, Salamero M, et al. Decreased striatal dopamine transporters uptake and substantia nigra hyperechogenicity as risk markers of synucleinopathy in patients with idiopathic rapid-eye-movement sleep behaviour disorder: a prospective study. Lancet Neurol. 2010;9:1070-7.

87. Postuma RB, Gagnon J-F, Vendette M, Desjardins C, Montplaisir JY. Olfaction and color vision identify impending neurodegeneration in rapid eye movement sleep behavior disorder. Ann Neurol. 2011;69:811-8.

88. Ahlskog JE. Beating a dead horse: dopamine and Parkinson disease. Neurology. 2007;69:1701-11.

89. Savica R, Rocca WA, Ahlskog JE. When does Parkinson disease start? Arch Neurol. 2010;67:798-801. 